\title{
Inhibitory Control was needed in Level-I Visual Perspective Taking: A Developing Negative Priming Study
}

\author{
Xiaodong $\mathrm{Li}^{1}$ \\ Meng Yuan (D) \\ Ping $X u^{2}$ \\ Wenyan $\mathrm{Wu} \mathbb{D}^{1}$ \\ 'School of Psychology, Shenzhen \\ University, Shenzhen, People's Republic of \\ China; ${ }^{2}$ College of Education, Wenzhou \\ University, Wenzhou, People's Republic \\ of China
}

\begin{abstract}
Aim: Previous studies have found that both children and adults have difficulties in dealing with judgments in which self-perspective differs from other-perspective, even in level1 perspective-taking. However, the underlying cognitive mechanism of this is still unclear. In the present study, we designed a negative priming (NP) paradigm of the dot-perspective task to examine whether inhibitory control was required to overcome egocentric bias in level-1 visual perspective-taking in children and adults. We observed an NP effect in both children $(n=43)$ and adults $(n=40)$. However, there was no significant difference between children and adults on the magnitude of the NP effect, indicating that when children could overcome the egocentric bias, they had inhibitory control ability comparable to that of adults in level-1 other-perspective-taking.

Background: Visual perspective-taking is an indispensable ability in social interaction; hence, it has attracted great attention from researchers. However, the mechanism underlying this process remains unclear. The present study aimed to investigate the role of inhibitory control in level-1 visual perspective-taking from a developmental perspective in order to understand the performance differences in perspective-taking tasks between children and adults.
\end{abstract}

Methods: The NP paradigm was applied to the dot-perspective task. Participants' response times (RTs) and error rates (ERs) were recorded during the experiment. A 2 (trial type: test vs control, within-subject) $\times 2$ (age: children vs adults) mix-design ANOVA was used to analyse the RTs and ERs data separately.

Results: We observed an NP effect for both children $(7.31, t(42)=2.78, p<0.01$, Cohen's $d=0.22)$ and adults $(27.58, t(39)=2.31, p<0.05$, Cohen's $d=0.21)$. However, the difference in the magnitude of the NP effect between children and adults was not significant $(t(81)=0.54, p=0.59)$

Conclusion: Inhibitory control was needed to overcome egocentric bias in level-1 visual perspective-taking for both children and adults. Moreover, when children could overcome egocentric bias, they had an inhibitory control ability comparable to that of adults.

Keywords: level-1 visual perspective-taking, inhibitory control, negative priming, egocentric bias

\section{Introduction}

Visual perspective-taking refers to the ability to predict the visual experience of another agent and is considered to be an adaptive function of humans. ${ }^{1}$ It helps people explain and predict the behaviour of others, thus promoting social interaction. ${ }^{2,3}$ Level-1 visual perspective-taking, the ability to know whether or 
not another person can see a given object, ${ }^{4,5}$ is one of the most basic forms of visual perspective-taking. However, previous studies have found that children have a systematic bias towards their own point of view when judging others' perspective. ${ }^{6}$ This phenomenon, known as "egocentric bias", has also been found in adults. ${ }^{7}$ Other studies have shown that even infants and non-human animals have some understanding of level-1 perspectivetaking tasks. ${ }^{8-11}$ Samson et al (2010) proposed that the specific experimental tasks used in these studies might allow infants and non-human animals to use some basic computation to process the other person's perspective with limited cognitive resources. To test this, Samson et al developed a dot perspective task, that was logically equivalent to infant tasks in terms of cognitive requirements, to investigate level-1 perspective-taking. The task displayed an avatar centred in a cartoon room in which some dots were displayed on the left and right walls. In the consistent trials, the participants and the avatar saw the same number of dots and in the inconsistent trials, the avatar saw fewer dots than the participants. When participants were called upon to judge from the avatar's perspective, the classic egocentric intrusion was found. ${ }^{12,13}$

Although both children and adults have shown difficulties in dealing with judgments in which self-perspective differs from other-perspective, the reason behind this is still unclear. Some researchers suggest that inhibition may play a role in level-1 perspective-taking. For example, Martin et al (2019) proposed that visual perspectivetaking requires the ability to distinguish one's own perspective from that of an alternative perspective and inhibit the irrelevant perspective. Qureshi et al (2010) found that concurrent tasks demanding inhibitory control affected perspective-taking and adult participants demonstrated stronger egocentric intrusions when performing dualtasks than single ones. ${ }^{14}$ Qureshi et al (2020) found that inhibitory control predicted adults' performance on a level-1 perspective-taking task and/or the director task. In addition to behavioural evidence, the role of inhibitory control in perspective taking is also supported by electroencephalography studies. These studies have found that when participants successfully resolved conflict between self- and other-perspectives, a network of prefrontal regions was activated, including the dorsolateral prefrontal cortex, which is associated with the inhibition of a prepotent response. ${ }^{15-17}$ Therefore, these studies suggest that inhibitory control might be involved in overcoming the egocentric bias in level-1 perspective-taking tasks.
However, the above studies have mainly adopted correlation designs or a dual-task paradigm; hence, they cannot demonstrate a causal relationship between inhibitory control and level-1 perspective-taking. To the best of our knowledge, no study has directly addressed the role of inhibitory control in level-1 perspective-taking.

In the present study, we designed a negative priming (NP) paradigm of the dot-perspective task to examine whether inhibitory control was needed to overcome egocentric bias in level-1 perspective-taking (see Figure 1). The NP paradigm is a classic design that investigates the role of inhibition in the process of selective attention, ${ }^{18}$ and its use has recently been extended to the field of learning. ${ }^{19-24}$ In addition, a recent study used the NP paradigm to demonstrate that inhibitory control was involved in spatial perspective-taking. ${ }^{25}$ The NP paradigm includes test trials and control trials that consist of prime and probe pairs occurring in sequence. The logic behind this is that if a stimulus or strategy is inhibited in the test prime stage, then the activation of the same stimulus or strategy will be impaired in the subsequent test probe stage, as reflected by a longer response time (RT) or a higher error rate (ER), compared to the performance on a control probe after an irrelevant control prime. ${ }^{26-28}$ Such impairment of performance caused by inhibition is called the NP effect. We expect an NP effect in level-1 perspective-taking.

Surtees and Apperly (2012) found that even though adults showed an egocentric bias similar to children, performance on perspective-taking improved with age. This result suggests that age-related perspective-taking improvement may be attributable to the increase in efficiency of inhibitory control, rather than a decrease in egocentrism. To test this theory, we included both children and adults in the present study. Since inhibitory control ability is not fully developed until adolescence, ${ }^{29}$ the ability to successfully inhibit irrelevant perspectives in inconsistent perspective-taking tasks should become more efficient with age. We hypothesised that: 1) children would be less efficient than adults in inconsistent perspective-taking tasks and 2) the magnitude of the NP effect would be smaller in adults than in children.

\section{Method}

\section{Participants}

$\mathrm{G}^{*}$ Power $3.1^{30}$ was utilized to calculate our sample size. We used an effect size of 0.38 ( $\eta^{2}$ fixed effects) as obtained from 
Test trials

Test prime item

(Inhibition of self- perspective required)

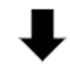

Test probe item

(Activation of self-perspective required)

\section{Control trials}

\section{Control prime item}

(No inhibition/activation of perspectives)

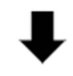

Control probe item

(Activation of self-perspective required)

Figure I The Negative-priming Paradigm of level-I perspective taking.

a previous NP study (Lubin et al, 2016), a statistical power of $80 \%$, and an $\alpha$ level of 0.05 . The calculation yielded a total sample size of 57 (inclusive of two age groups). To be conservative, we recruited 83 participants, including 43 fourth-grade children ( 27 boys, 16 girls; mean age: $10.37 \pm$ 0.49 years, range: $10-11$ years), and 40 young adults ( 28 males and 12 females; mean age: $20.58 \pm 2.73$ years, range: 18-30 years). All children came from the same primary school in Shenzhen, China, and all young adults were undergraduates or graduates at Shenzhen University. All participants were right-handed and reported normal or corrected-to-normal vision. None of them had participated in a similar experiment before. All participants or their guardians provided informed consent and the study was verified in accordance with the national and international norms of research on human participants. The present study was conducted in accordance with the principles of the Declaration of Helsinki.

\section{Material}

As in the study conducted by Samson et al (2010), the stimuli were pictures showing an avatar standing in the centre of a room with three visible walls (left, right, and centre). As shown in Figure 2, the avatar was facing either the left or the right wall in which 0 to 3 coloured dots were presented. Participants were required to evaluate the number of dots that were visible from their own perspective or from the perspective of the avatar. Three types of tasks were employed in this study: congruent, incongruent, and neutral. For the congruent tasks, dots were presented only in the wall that the avatar faced, and the participants and avatar could see the same number of dots. Here, participants were only required to respond to their own point of
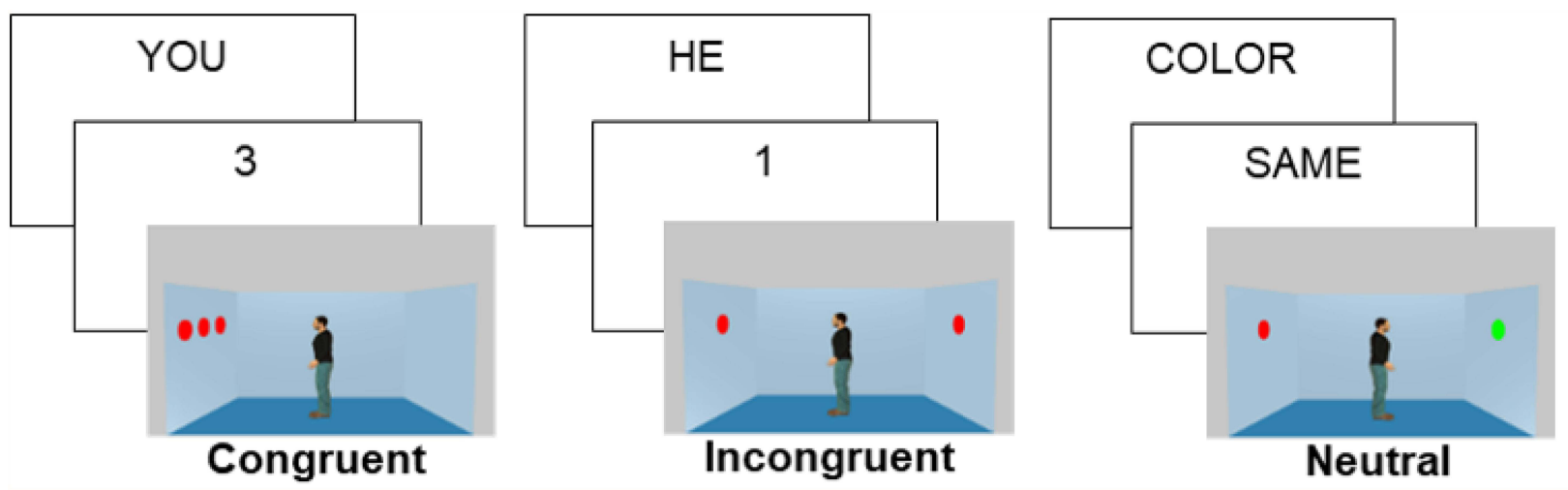

Figure 2 Samples of the three types of tasks in the dot-perspective task. 
view. For the incongruent tasks, dots were presented in both the left and right walls. The number of dots seen by the participants and avatar was different. Hence, participants were required to inhibit their own perspective and adopt the avatar's point of view. For the neutral tasks, one dot was presented on each side of the wall, and participants were required to judge whether the colours of the two dots were the same. The neutral tasks were set such that self-perspective was neither congruent nor incongruent with other-perspective. For each type of task, half of the avatars faced the left wall and the other half faced the right wall. The gender of the avatars was set to be the same as the gender of the participant. In total, we created 48 congruent items, 24 incongruent items, and 24 neutral items.

The NP paradigm evidences the inhibition process by showing that the performance of the congruent task will be impaired if it follows an incongruent task that demands inhibition. To this end, the experiment included test trials and control trials, with each trial consisting of a prime and a probe (see Figure 3). The test trial was distinguished from the control trial only in the prime, which was an incongruent task for the test and a neutral task for the control. This was done to ascribe inferior or slower performance of test probes (ie, NP effect) to the reactivation process of the inhibited self-perspective in the test trial.

\section{Procedure}

Participants were tested individually in a lab, seated approximately $75 \mathrm{~cm}$ from a laptop computer with a screen resolution of $1280 \times 768$ pixels. Stimuli were presented using E-prime 2.0 (Psychological Software Tools, Inc., Pittsburgh, PA). First, participants conducted 12 practice dot-judgments with four judgments for each of the congruent, incongruent, and neutral tasks. They then performed two test trials and two control trials. These trials were presented randomly and were not required for the formal experiment.

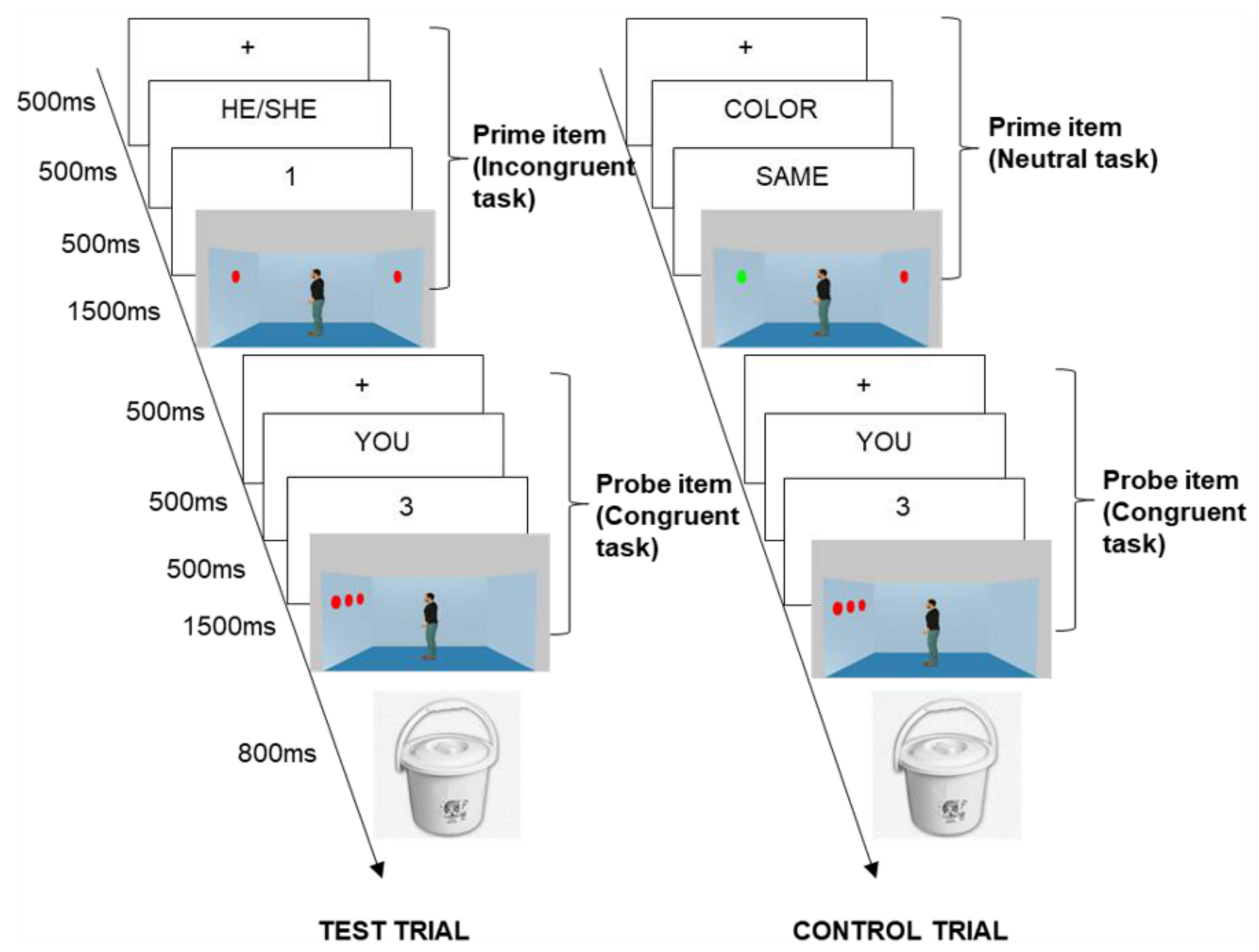

Figure 3 Example of prime-probe sequences in control and test trials. 
Table I Response Times (Ms) and Error Rates (\%) on the Primes and Probes in the Control and Test Conditions of the DotPerspective Task in Children and Adults

\begin{tabular}{|l|c|c|c|c|}
\hline \multirow{2}{*}{} & \multicolumn{2}{|c|}{ RTs (ms) } & \multicolumn{2}{c|}{ Error Rates (\%) } \\
\cline { 2 - 5 } & Children $(\boldsymbol{n}=\mathbf{4 3})$ & Adults $(\boldsymbol{n}=\mathbf{4 0})$ & Children $(\mathbf{n}=\mathbf{4 3})$ & Adults $(\boldsymbol{n}=\mathbf{4 0})$ \\
\hline Prime & & & & \\
Control & $672.85(182.46)$ & $688.18(138.97)$ & $3.54(13.84)$ & $11.67(7.02)$ \\
Test & $784.07(232.47)$ & $789.96(130.99)$ & $32.20(16.21)$ & \\
\hline Probe & & & & $3.80(4.69)$ \\
Control & $718.09(164.31)$ & $694.69(121.81)$ & $17.25(12.72)$ & $5.87(4.59)$ \\
Test & $755.41(168.85)$ & $722.26(135.14)$ & $23.61(13.63)$ & $2.06(6.00)$ \\
NP effect & $37.31(87.98)$ & $27.58(75.65)$ & $6.37(9.12)$ & \\
\hline
\end{tabular}

The formal experiment consisted of two blocks, each consisting of 50 trials (24 test and 24 control trials of prime-probe pairs, and two filter trials). The two filters were used to prevent participants from forming a rigid response (see Appendix A for a more detailed explanation). The primes and probes in both the test and control trials were "yes" or "no" judgments. More specifically, as shown in Figure 3, following the presentation of a fixation cross for 500 milliseconds (ms) and a blank screen for 400 $\mathrm{ms}$, the word "YOU" (congruent tasks) or "HE"/ "SHE"(incongruent tasks) were presented to guide participants to take their own perspective or that of the avatar, respectively. After $500 \mathrm{~ms}$, a digital number, ranging from $0-3$, appeared to specify the number of dots that the participants needed to verify in the subsequent picture. Finally, the picture was presented for $1500 \mathrm{~ms}$, during which participants needed to verify (with "yes"/"no" responses) whether the number of dots shown in the picture corresponded with the number specified in the preceding screen. The procedure for the neutral prime was similar except that the task was to determine whether the colour of the dots shown in the left and right walls were the same. Participants were requested to press the "J" key if the answer was "Yes", and the "F" key if the answer was "No". The ratio of "yes" or "no" trials account for $50 \%$ respectively in all conditions. As shown in Figure 3, an incongruent prime with a congruent probe formed a test trial, and a neutral prime with a congruent probe formed a control trial. Between trials, a pixel image $(400 \times 400)$ of a neutral object (eg a bucket) was inserted for $800 \mathrm{~ms}$ to prevent transfer effects. ${ }^{32}$ The trials were provided in a pseudorandom order so that no more than three control or test trials could occur successively. The RTs and ERs were recorded.

\section{Results}

All participants were included in the analysis. However, by definition, the NP effect could be observed only when the responses to the primes were correct; hence, for RTs only, the analysis was based on trials in which participants responded correctly to both primes and probes $(37.80 \%$ of the trials were deleted for children and $12.37 \%$ for adults). Median RTs were calculated for these trials, because the median is not susceptible to skewed data or outliers. ${ }^{19,33}$ Descriptive statistics are presented in Table 1.

A series of 2 (trial type: test vs control, within-subject) $\times 2$ (age: children vs adults) mix-design ANOVAs were conducted on the ERs and RTs separately. We declared the effect sizes (either partial eta squared in the ANOVA or Cohen's $\mathrm{d}$ in the differences of means) for significant effects.

\section{Primes}

For ERs, a significant main effect of age was detected, $F(1,81)=60.60, p<0.001, \eta^{2}=0.43$. There was also a significant main effect of trial type, $F(1,81)=56.44$, $p<0.001, \eta^{2}=0.41$. The interaction between age and trial type was significant, $F(1,81)=8.03, p<0.01, \eta^{2}=0.09$. Further simple effect analyses indicated that, for both children and adults, participants committed more errors in the test trials than in the control trials (children: $32.20 \%$ vs $17.54 \%, p<0.001$, Cohen's $d=0.97$; adults: $11.67 \%$ vs $5.03 \%, p<0.001$, Cohen's $d=1.11)$. Children committed more errors than adults in both test (children vs adults: $32.20 \%$ vs $11.67 \%, p<0.001$, Cohen's $d=1.64$ ) and control trials (children vs adults: $17.54 \%$ vs $5.03 \%$, $p<0.001$, Cohen's $d=1.21$ ).

For RTs, there was no significant difference between children and adults, $F(1,81)=0.08, p=0.78$. The main 
effect of trial type was significant, $F(1,81)=75.00, p<$ $0.001, \eta^{2}=0.48$, participants needed more time to perform the incongruent tasks $(M=786.91 \mathrm{~ms})$ than the neutral tasks $(M=680.23 \mathrm{~ms})$. There was no significant interaction between age and trial type $(F(1,81)=0.15, p=0.70)$.

\section{Probes}

For ERs, a significant main effect of age was detected, $F(1,81)=59.09, p<0.001, \eta^{2}=0.42$. There was also a significant main effect of trial type, $F(1,81)=24.36$, $p<0.001, \eta^{2}=0.23$. The interaction between age and trial type was significant, $F(1,81)=6.35, p<0.05, \eta^{2}=0.07$. Further simple effect analyses indicated that children committed more errors in the test trials $(23.61 \%)$ than in the control trials $(17.25 \%), p<0.001$ Cohen's $d=0.48$; there was no significant difference between the test and control trials for adults $(p=0.10)$. In addition, children committed more errors than adults in both test (children vs adults: $23.61 \%$ vs $5.87 \%, p<0.001$, Cohen's $d=1.74)$ and control trials (children vs adults: $17.25 \%$ vs $3.80 \%, p<$ 0.001, Cohen's $d=1.40$ ).

For RTs, there was no significant difference between children and adults, $F(1,81)=0.80, p=0.37$. There was a significant main effect of trial type, $F(1,81)=12.89$, $p<0.001, \eta^{2}=0.14$; participants responded more slowly to the congruent tasks in the test trials than in the control trials. There was no significant interaction between age and trial type $(F(1,81)=0.29, p=0.59)$. The difference in the magnitude of the NP effect between children and adults was not significant $(t(81)=0.54, p=0.59)$.

\section{Primes versus Probes Analyses}

To determine whether the cognitive costs of taking otherperspective are more than those of taking self-perspective, we conducted a 2 (perspective: other vs self) $\times 2$ (age: children vs adults) mixed-design ANOVA. We included RTs and ERs for the test primes (ie, incongruent otherperspective items) and control probes (ie, congruent selfperspective) (for a similar approach, see Aïte et al, 2016).

For ERs, the ANOVA revealed a significant main effect of task type, $F(1,81)=78.21, p<0.001, \eta^{2}=0.49$, and a main effect of age, $F(1,81)=64.52, p<0.001, \eta^{2}=$ 0.44 . There was a significant interaction between age and task type $\left(F(1,81)=7.55, p<0.01, \eta^{2}=0.09\right.$. Further simple effect analyses indicated that, for both children and adults, participants committed more errors in the incongruent tasks than in the congruent tasks (children: $32.20 \%$ vs $17.25 \%, p<0.001$, Cohen's $d=1.03$; adults: $11.67 \%$ vs
$3.80 \%, p<0.001$, Cohen's $d=1.32$ ). Children committed more errors than adults in both incongruent (children vs adults: $32.20 \%$ vs $11.67 \%, p<0.001$, Cohen's $d=1.64$ ) and congruent tasks (children vs adults: $17.25 \%$ vs $3.80 \%$, $p<0.001$, Cohen's $d=1.40$ ).

For RTs, a main effect of task type was found, $F(1,81)$ $=41.67, p<0.001, \eta^{2}=0.34$; response time for the incongruent tasks $(M=786.91 \mathrm{~ms})$ was longer than that for the congruent tasks $(M=718.09 \mathrm{~ms})$. There was no significant difference between children and adults $(F(1,81)=0.06, p=0.80)$ and no interaction between age and task type $(F(1,81)=1.38, p=0.2)$.

\section{Discussion}

Generally, researchers believe that level-2 perspectivetaking is more effortful and demands inhibitory control; ${ }^{34}$ level-1 perspective-taking is considered easier; therefore, infants and some non-human animals with limited cognitive capacity also possess this ability. ${ }^{11,35,36}$ The current study demonstrated, for the first time, that inhibitory control was also needed to override egocentric bias in level1 perspective-taking for both older children and adults.

The dot perspective task was created to directly compare the level-1 perspective-taking ability between children and adults. Consistent with previous studies, ${ }^{12,37,38}$ the present study found that both children and adults made more errors and responded more slowly when judging how many dots the avatar could see than how many dots they themselves could see. This result suggests that egocentric bias does not disappear with age and provides evidence against Piaget's theory that claims that egocentric bias disappears after children obtain decentration. ${ }^{39-41}$ In contrast, it favours the argument that different views and learning strategies co-exist, as claimed by theories from the Neo-Piaget approach, such as the overlapping waves model. ${ }^{42-44}$ Although our results suggest that the size of egocentric bias does not decrease with age, we found that children performed less accurately than adults in all three types of level-1 perspective-taking tasks and responded as quickly as adults. This is inconsistent with the theoretical assumption of speed-accuracy trade-offs, which is that the RT would be shorter when the ER is higher. ${ }^{45}$ Therefore, children's higher ERs should be due to their inferior general cognitive ability.

Recently, debates on the dot perspective task have focussed on whether it reflects the automatic process of level-1 perspective-taking (ie, sub-mentalizing hypothesis ${ }^{13}$ ), or whether it is related to attentional cueing 
effects produced by the avatar's gaze direction (ie, directional account ${ }^{2,46,47}$ ). For example, Furlanetto et al (2016) found that there was a consistency effect when the avatar wore a transparent goggle, but not when the avatar wore an opaque goggle, which is in line with the submentalizing hypothesis. ${ }^{13}$ However, Cole et al (2016) demonstrated consistency effects in both transparent and opaque barrier conditions, showing evidence against the sub-mentalizing hypothesis but supporting the attentional cueing effects of level-1 perspective-taking. ${ }^{48}$ Although the arguments for the automatic processing of level-1 perspective-taking are controversial, these studies demonstrated that the egocentric bias was robust, showing that the performance on congruent tasks would be better than that on incongruent tasks.

Later, researchers proposed that perspective switching may be a potential effect of egocentric bias in level-1 perspective-taking. ${ }^{49}$ They tested this hypothesis by comparing participants' performance between stick trials (ie, trials that tapped the same perspective; (you-) YOU or (they-) THEY) and switch trials (ie, trials that tapped different perspectives; (you-) THEY or (they-) YOU). However, they found that egocentric intrusions were robust and comparable in both stick and switch trial types. The result suggests that the egocentric bias in level-1 perspectivetaking is not caused by perspective switching, but may be due to other implicit processing. Therefore, we conducted this study to shed light on the role of inhibitory control in level-1 perspective-taking using an NP paradigm.

Importantly, we found an NP effect showing that selfperspective judgments were slower when they were preceded by incongruent other-perspective primes than when preceded by neutral primes. This result indicated that when making incongruent other-perspective judgments, self-perspective-taking was inhibited; hence, it required more time to be reactivated in subsequent selfperspective judgments. Therefore, the NP effect provided direct evidence of inhibitory control in level-1 perspectivetaking. However, we found no significant difference in the efficiency of inhibitory control between children and adults. This result is consistent with that of previous studies, which suggest that the capacity to override cognitive biases might increase with age; however, once individuals are able to successfully overcome these biases, the efficiency of inhibitory control is comparable..$^{20,22}$

The findings are controversial because they evaluate whether the magnitude of NP effects differs between children and adults. Our results were consistent with those of studies using arithmetic word problems, ${ }^{22}$ geometric comparison tasks, ${ }^{20}$ and mathematical reasoning problems. ${ }^{19,31}$ These studies did not find age differences between children and adults in the NP effect. However, other researchers have found the magnitude of the NP effect to be greater in children than in adults in tasks such as the Piaget-like class-inclusion task, ${ }^{42}$ the verb inflection task, ${ }^{50}$ and level2 perspective-taking tasks. ${ }^{25}$ A common explanation for this discrepancy is that there are two kinds of inhibition: automatic inhibition in ignoring physical stimuli and intentional inhibition to overcome misleading strategies. ${ }^{22,51}$ The age difference in NP magnitude might depend on the relative involvement of the two types of inhibition in a specific task. The more intentional inhibition needed, the more likely there was an age difference in NP magnitude. In the current study, the dot perspective task was a level1 perspective-taking task, which was quite simple for both children and adults and did not involve too much intentional inhibition.

By directly measuring inhibitory ability with tasks such as a Stroop task, some studies demonstrated that executive functioning, including inhibitory control, was related to children's theory of $\mathrm{mind}^{52}$ and level-2 perspectivetaking ability. ${ }^{53}$ However, as Frick and Baumeler (2017) indicated, these correlational studies could not verify the causal relationship between inhibitory control and perspective-taking. Furthermore, although the performance of inhibitory control tasks was related to that of perspectivetaking tasks, the relationship itself could not demonstrate how inhibitory control functions when perspective tasks are conducted..$^{25,54,55}$ The NP paradigm could solve this problem by inhibiting the specific perspective in the prime stage, then reactivating the same perspective in the probe stage; the longer RT or less accuracy on probes was an indicator of inhibition.

One argument is that the longer RT on probes in the test trials may be a switch cost difference because incongruent tasks are more difficult than neutral tasks. However, previous studies have demonstrated higher switch costs for betweentasks than for within-tasks. ${ }^{56}$ In the present study, the incongruent primes and congruent probes in the test trials were both perspective-taking tasks, while the neutral tasks in the control trial were colour-matching tasks. Therefore, the switch cost in the control trials should be greater than that in the test trials. The longer RT on the probes in the test trials could not be attributed to the switch cost difference in the present study. Moreover, a recent study found that inhibition best forecasted young adults' perspective-taking, while switching cost best 
predicted older adults' perspective taking. ${ }^{57}$ The participants in the current study were adolescents and young adults. Thus, impaired performance in the test trials was more likely due to preceding inhibition rather than switch costs.

Another argument is that the longer RT on test probes may result from mentally taxing differences caused by the different difficulty levels between incongruent and neutral items. However, the difficulty of the preceding trials had an impact on the subsequent trials only after prolonged exposure to the difficult trials. Our experiment, on the other hand, presented trials one after the other. Moreover, our subjects were not given any feedback during the experiment, which has been shown to be a key factor in evoking a hysteresis effect. ${ }^{58}$ Therefore, the impaired performance on the test probes may not be due to different difficulty levels between the test and control trials. Nevertheless, we believe that this is a limitation of the present study, and future studies should, ideally, use neutral prime tasks that are equated with or even slightly more difficult than inconsistent prime tasks, exclude the requirement of selfperspective inhibition, or use ERP/fMRI to explore the inhibitory control mechanism in level-1 perspective-taking. In addition, the subjects' sex ratio was disproportionate in the current study. Although previous studies have not found gender differences in visual perspective-taking, ${ }^{59}$ we suggest that future research should aim to overcome these shortcomings.

To conclude, we provided direct evidence that taking a level-1 visual perspective requires inhibitory control to overcome egocentric bias for both older children and adults.

\section{Acknowledgment}

This manuscript was supported by a grant from the Chinese National Office of Education Sciences Planning (BBA170062).

\section{Disclosure}

The authors report no known conflicts of interest for this work.

\section{References}

1. Michelon P, Zacks JM. Two kinds of visual perspective taking. Percept Psychophys. 2006;68(2):327-337. doi:10.3758/BF03193680

2. Conway JR, Lee D, Ojaghi M, Catmur C, Bird G. Submentalizing or mentalizing in a Level 1 perspective-taking task: a cloak and goggles test. J Exp Psychol Hum Percept Perform. 2017;43(3):454-465. doi:10.1037/xhp0000319

3. Eyal T, Steffel M, Epley N. Perspective mistaking: accurately understanding the mind of another requires getting perspective, not taking perspective. J Pers Soc Psychol. 2018;114(4):547-571. doi:10.1037/ pspa0000115
4. Flavell JH, Everett BA, Croft K, Flavell ER. Young children's knowledge about visual perception: further evidence for the Level 1-Level 2 distinction. Dev Psychol. 1981;17(1):99-103. doi:10.1037/00121649.17.1.99

5. Masangkay ZS, McCluskey KA, McIntyre CW, Sims-Knight J, Vaughn BE, Flavell JH. The early development of inferences about the visual percepts of others. Child Dev. 1974;45(2):357. doi:10.2307/1127956

6. Surtees ADR, Apperly IA. Egocentrism and Automatic Perspective Taking in Children and Adults: egocentrism and Automatic Perspective Taking. Child Dev. 2012;83(2):452-460. doi:10.1111/ j.1467-8624.2011.01730.x

7. Todd AR, Cameron CD, Simpson AJ. Dissociating processes underlying level-1 visual perspective taking in adults. Cognition. 2017;159:97-101. doi:10.1016/j.cognition.2016.11.010

8. Hare B, Call J, Agnetta B, Tomasello M. Chimpanzees know what conspecifics do and do not see. Anim Behav. 2000;59(4):771-785. doi:10.1006/anbe.1999.1377

9. Luo Y, Baillargeon R. Do 12.5-month-old infants consider what objects others can see when interpreting their actions? Cognition. 2007;105(3):489-512. doi:10.1016/j.cognition.2006.10.007

10. Sodian B, Thoermer C, Metz U. Now I see it but you don't: 14-montholds can represent another person's visual perspective. Dev Sci. 2007;10 (2):199-204. doi:10.1111/j.1467-7687.2007.00580.x

11. Song H, Baillargeon R. Infants' reasoning about others' false perceptions. Dev Psychol. 2008;44(6):1789-1795. doi:10.1037/ a0013774

12. Samson D, Apperly IA, Braithwaite JJ, Andrews BJ, Bodley Scott SE. Seeing it their way: evidence for rapid and involuntary computation of what other people see. J Exp Psychol Hum Percept Perform. 2010;36(5):1255-1266. doi:10.1037/a0018729

13. Furlanetto T, Becchio C, Samson D, Apperly I. Altercentric interference in level 1 visual perspective taking reflects the ascription of mental states, not submentalizing. J Exp Psychol Hum Percept Perform. 2016;42(2):158-163. doi:10.1037/xhp0000138

14. Qureshi AW, Apperly IA, Samson D. Executive function is necessary for perspective selection, not Level-1 visual perspective calculation: evidence from a dual-task study of adults. Cognition. 2010;117 (2):230-236. doi:10.1016/j.cognition.2010.08.003

15. Qureshi AW, Monk RL, Samson D, Apperly IA. Does interference between self and other perspectives in theory of mind tasks reflect a common underlying process? Evidence from individual differences in theory of mind and inhibitory control. Psychon Bull Rev. 2020;27 (1):178-190. doi:10.3758/s13423-019-01656-z

16. Aron AR, Robbins TW, Poldrack RA. Inhibition and the right inferior frontal cortex: one decade on. Trends Cogn Sci. 2014;18(4):177-185. doi:10.1016/j.tics.2013.12.003

17. Thirioux B, Mercier MR, Jorland G, Berthoz A, Blanke O. Mental Imagery of Self-Location during Spontaneous and Active Self-Other Interactions: an Electrical Neuroimaging Study. J Neurosci. 2010;30 (21):7202-7214. doi:10.1523/JNEUROSCI.3403-09.2010

18. Tipper SP. The Negative Priming Effect: inhibitory Priming by Ignored Objects. Quarterly J Exp Psychol Section A. 1985;37 (4):571-590. doi:10.1080/14640748508400920

19. Jiang R, Li X, Xu P, Mao T. Why students are biased by heuristics: examining the role of inhibitory control, conflict detection, and working memory in the case of overusing proportionality. Cogn Dev. 2020;53:100850. doi:10.1016/j.cogdev.2020.100850

20. Jiang $\mathrm{R}, \mathrm{Li} \mathrm{X}, \mathrm{Xu} \mathrm{P}$, Chen $\mathrm{Y}$. Inhibiting intuitive rules in a geometry comparison task: do age level and math achievement matter? J Exp Child Psychol. 2019;186:1-16. doi:10.1016/j. jecp.2019.05.003

21. Jiang R, Li X, Xu P, Zhong L, Lei Y. The role of inhibitory control in overcoming English written-verb inflection errors: evidence from Chinese ESL learners. Curr Psychol. 2019. doi:10.1007/s12144019-00482-9 
22. Lubin A, Vidal J, Lanoë C, Houdé O, Borst G. Inhibitory control is needed for the resolution of arithmetic word problems: a developmental negative priming study. J Educ Psychol. 2013;105 (3):701-708. doi:10.1037/a0032625

23. Lubin A, Rossi S, Lanoë C, Vidal J, Houdé O, Borst G. Expertise, inhibitory control and arithmetic word problems: a negative priming study in mathematics experts. Learn Instruction. 2016;45:40-48. doi:10.1016/j.learninstruc.2016.06.004

24. Roell M, Viarouge A, Houdé O, Borst G. Inhibition of the whole number bias in decimal number comparison: a developmental negative priming study. $J$ Exp Child Psychol. 2019;177:240-247. doi:10.1016/j.jecp.2018.08.010

25. Aïte A, Berthoz A, Vidal J, et al. Taking a Third-Person Perspective Requires Inhibitory Control: evidence From a Developmental Negative Priming Study. Child Dev. 2016;87(6):1825-1840. doi:10.1111/cdev.12558

26. Houdé O, Borst G. Measuring inhibitory control in children and adults: brain imaging and mental chronometry. Front Psychol. 2014;5. doi:10.3389/fpsyg.2014.00616.

27. Houdé O. Inhibition and cognitive development: object, number, categorization, and reasoning. Cogn Dev. 2000;15(1):63-73. doi:10.1016/S0885-2014(00)00015-0

28. Tipper SP. Does Negative Priming Reflect Inhibitory Mechanisms? A Review and Integration of Conflicting Views. Quarterly J Exp Psychol Section A. 2001;54(2):321-343. doi: $10.1080 / 713755969$

29. Luna B, Padmanabhan A, O'Hearn K. What has fMRI told us about the Development of Cognitive Control through Adolescence? Brain Cogn. 2010;72(1):101-113. doi:10.1016/j.bandc.2009.08.005

30. Faul F, Erdfelder E, Buchner A, Lang A-G. Statistical power analyses using $\mathrm{G}^{*}$ Power 3.1: tests for correlation and regression analyses. Behav Res Methods. 2009;41(4):1149-1160. doi:10.3758/BRM.41. 4.1149

31. Jiang $\mathrm{R}$, Li X. The overuse of proportional reasoning and its cognitive mechanism: a developmental negative priming study. Acta Psychologica Sinica. 2017;49(6):745. doi:10.3724/SP.J.1041.20 17.00745

32. Fritz J, Dreisbach G. The Time Course of the Aversive Conflict Signal. Exp Psychol. 2015;62(1):30-39. doi:10.1027/1618-3169/ a000271

33. Hilbig BE, Pohl RF. Ignorance- versus evidence-based decision making: a decision time analysis of the recognition heuristic. $J \operatorname{Exp}$ Psychol Learn Mem Cogn. 2009;35(5):1296-1305. doi:10.1037/ a0016565

34. Apperly IA, Butterfill SA. Do humans have two systems to track beliefs and belief-like states? Psychol Rev. 2009;116(4):953-970. doi:10.1037/a0016923

35. Kaminski J, Riedel J, Call J, Tomasello M. Domestic goats, Capra hircus, follow gaze direction and use social cues in an object choice task. Anim Behav. 2005;69(1):11-18. doi:10.1016/j.anbehav.2004 05.008

36. Tomasello M, Carpenter M, Call J, Behne T, Moll H. Understanding and sharing intentions: the origins of cultural cognition. Behav Brain Sci. 2005;28(5):675-691. doi:10.1017/S0140525X05000129

37. Crescentini C, Fabbro F, Urgesi C. Mental spatial transformations of objects and bodies: different developmental trajectories in children from 7 to 11 years of age. Dev Psychol. 2014;50(2):370-383 doi: $10.1037 / \mathrm{a} 0033627$

38. Gronholm PC, Flynn M, Edmonds CJ, Gardner MR. Empathic and non-empathic routes to visuospatial perspective-taking. Conscious Cogn. 2012;21(1):494-500. doi:10.1016/j.concog.2011.12.004

39. Peel EA, Piaget J. The Child's Conception of Number. Br J Educ Stud. 1953;1(2):183. doi:10.2307/3118763

40. Piaget J. Piaget's Theory. In: Inhelder B, Chipman $\mathrm{HH}$, Zwingmann C editors. Piaget and His School. Springer Berlin Heidelberg; 1976:11-23. doi:10.1007/978-3-642-46323-5_2.
41. Wheeler DH, Inhelder B, Piaget J. The Early Growth of Logic in the Child. Mathematical Gazette. 1965;49(368):220. doi:10.2307/ 3612335

42. Borst G, Poirel N, Pineau A, Cassotti M, Houdé O. Inhibitory control in number-conservation and class-inclusion tasks: a neo-Piagetian inter-task priming study. Cogn Dev. 2012;27(3):283-298. doi:10. 1016/j.cogdev.2012.02.004

43. Siegler RS. Cognitive variability. Dev Sci. 2007;10(1):104-109. doi:10.1111/j.1467-7687.2007.00571.x

44. Siegler RS. How Does Change Occur: a Microgenetic Study of Number Conservation. Cogn Psychol. 1995;28(3):225-273. doi:10. 1006/cogp.1995.1006

45. Ivanoff J, Branning P, Marois R. fMRI Evidence for a Dual Process Account of the Speed-Accuracy Tradeoff in Decision-Making. PLoS One. 2008;3(7):e2635. doi:10.1371/journal.pone.0002635

46. Santiesteban I, Catmur C, Hopkins SC, Bird G, Heyes C. Avatars and arrows: implicit mentalizing or domain-general processing? $J$ Exp Psychol Hum Percept Perform. 2014;40(3):929-937. doi:10.1037/ $\mathrm{a} 0035175$

47. Santiesteban I, Kaur S, Bird G, Catmur C. Attentional processes, not implicit mentalizing, mediate performance in a perspective-taking task: evidence from stimulation of the temporoparietal junction. NeuroImage. 2017;155:305-311. doi:10.1016/j.neuroimage.2017.04. 055

48. Cole GG, Atkinson M, Le ATD, Smith DT. Do humans spontaneously take the perspective of others? Acta Psychologica. 2016;164:165-168. doi:10.1016/j.actpsy.2016.01.007

49. Ferguson HJ, Apperly I, Cane JE. Eye tracking reveals the cost of switching between self and other perspectives in a visual perspective-taking task. Quarterly $J$ Exp Psychol. 2017;70 (8):1646-1660. doi:10.1080/17470218.2016.1199716

50. Lanoë C, Vidal J, Lubin A, Houdé O, Borst G. Inhibitory control is needed to overcome written verb inflection errors: evidence from a developmental negative priming study. Cogn Dev. 2016;37:18-27. doi:10.1016/j.cogdev.2015.10.005

51. Pritchard VE, Neumann E. Avoiding the potential pitfalls of using negative priming tasks in developmental studies: assessing inhibitory control in children, adolescents, and adults. Dev Psychol. 2009;45 (1):272-283. doi:10.1037/a0014168

52. Hamilton AF, Brindley R, Frith U. Visual perspective taking impairment in children with autistic spectrum disorder. Cognition. 2009;113 (1):37-44. doi:10.1016/j.cognition.2009.07.007

53. Frick A, Baumeler D. The relation between spatial perspective taking and inhibitory control in 6-year-old children. Psychol Res. 2017;81 (4):730-739. doi:10.1007/s00426-016-0785-y

54. Lin S, Keysar B, Epley N. Reflexively mindblind: using theory of mind to interpret behavior requires effortful attention. J Exp Soc Psychol. 2010;46(3):551-556. doi:10.1016/j.jesp.2009.12.019

55. Wardlow L. Individual differences in speakers' perspective taking: the roles of executive control and working memory. Psychon Bull Rev. 2013;20(4):766-772. doi:10.3758/s13423-013-0396-1

56. Philipp AM, Kalinich C, Koch I, Schubotz RI. Mixing costs and switch costs when switching stimulus dimensions in serial predictions. Psychol Res. 2008;72(4):405-414. doi:10.1007/s00426-008-0150-x

57. Long MR, Horton WS, Rohde H, Sorace A. Individual differences in switching and inhibition predict perspective-taking across the lifespan. Cognition. 2018;170:25-30. doi:10.1016/j.cognition.2017. 09.004

58. Odic D, Hock H, Halberda J. Hysteresis affects approximate number discrimination in young children. J Exp Psychol Gen. 2014;143 (1):255-265. doi:10.1037/a0030825

59. Zancada-Menendez C, Sampedro-Piquero P, Lopez L, McNamara TP. Age and gender differences in spatial perspective taking. Aging Clin Exp Res. 2016;28(2):289-296. doi:10.1007/s40520-015-0399-z 


\section{Publish your work in this journal}

Psychology Research and Behavior Management is an international, peer-reviewed, open access journal focusing on the science of psychology and its application in behavior management to develop improved outcomes in the clinical, educational, sports and business arenas. Specific topics covered in the journal include: Neuroscience, memory and decision making; Behavior modification and management; Clinical

applications; Business and sports performance management; Social and developmental studies; Animal studies. The manuscript management system is completely online and includes a very quick and fair peer-review system, which is all easy to use. Visit http://www. dovepress.com/testimonials.php to read real quotes from published authors.

Submit your manuscript here: https://www.dovepress.com/psychology-research-and-behavior-management-journal 